\title{
Assessing Ethanol Yield from Fermented Juice of Local and Exotic Sweet Sorghum Varieties Grown in Sudan
}

\author{
Salma I. Abdalbagi ${ }^{1, b}$ and Maarouf I. Mohammed ${ }^{2, \mathrm{a}^{*}}$ \\ ${ }^{1}$ Forage \& Range Research Program, Shambat Research Station, \\ Khartoum, Sudan. \\ ${ }^{2}$ Forage Improvement Program, Agricultural Research Corporation (ARC), \\ Khartoum North, Sudan. \\ amaaroufibrahim@gmail.com, bsalmaebrahim25@hotmail.com
}

Keywords: Theoretical ethanol, Ankolib, baker's yeast, ethanol percentage, brix

\begin{abstract}
An experiment was conducted in 2017 at Alwaha Project, Khartoum State to study the potential of ethanol yield from fermented juice of local and exotic sweet sorghums. 40 genotypes were arranged in RCB design. Juice yield, ethanol yield as percentage of fermented juice, actual and theoretical ethanol yields were studied. The Baker's yeast (Saccharomyces cerevisiae) was used in the fermentation process. ANOVA tests, correlation and regression analysis of actual vs theoretical ethanol yield were performed. Significant differences were detected among genotypes for ethanol yields. High ethanol yields as percentage from fermented juice were obtained, but ethanol yield per hectare was relatively low due to low juice yields. The genotypes BlueRibbon and KensasCollies from exotic materials; 5AbjSG51 and S.154 Ab70 from local materials were identified as promising for ethanol production. Correlation between actual ethanol yield and Juice yield was positive and highly significant. Regression analysis indicated that theoretical ethanol yield was little bit overestimated. It was concluded that juice yield is more crucial than ethanol concentration in maximizing ethanol yield of sweet sorghum. More efforts are needed to develop high juice-yielding genotypes. Juice maximization can also be achieved by using efficient milling devices and optimizing cultural practices.
\end{abstract}

\section{Introduction}

Sorghum (Sorghum bicolor (L.) Moench) is the most important crop grown for food and feed in Sudan where it believed to be domesticated and/or diversified [1,2]. Sweet sorghum is a type of sorghum with unique ability to accumulate sweet juice in the stalk just like sugarcane [3] along with having the potential for grain and forage production. Encouraged by the great diversity of sorghum in Sudan, a research project had been initiated in 2012 to develop multi-purpose varieties compromising feed, food and fuel attributes [4]. The results obtained pointed to the possibility of developing varieties simultaneously improved in stem-sugar, grain and stover attributes [5]. Other research studied the performance of local and exotic sweet sorghum genotypes for theoretical ethanol yield at different sowing dates. Theoretical ethanol yield was calculated based on juice yield and brix reading. The results obtained revealed some materials with theoretical yields higher than or comparable to those reported in India and USA. However, determination of the actual ethanol yield by extraction from fermented juice was thought essential to confirm the theoretical results. Alcoholic fermentation using the Baker's yeast (Saccharomyces cerevisiae) is usually used to convert sugars into ethanol [6] with conversion efficiency varying from $85 \%$ to $95 \%$ of theoretical yield [7]. The objective of this study was to investigate the potential of ethanol yield from fermented juice of local and exotic sweet sorghum varieties grown in the Sudan. 


\section{Materials and Methods}

\section{The plant materials}

Forty sorghum genotypes representing 3 groups as detailed in Table 1 were studied.

Table 1. The plant materials used in the study

\begin{tabular}{|l|l|l|l|}
\hline S. No. & Group 1 & Group 2 & Group 3 \\
\hline 1 & Waconia-L & ANK. S.18 & 1AbjSG51 \\
\hline 2 & Red-x & ANK.LzmNrs & 2AbjSG51 \\
\hline 3 & N98 & ANK. S.36 & 3AbjSG51 \\
\hline 4 & Brawley & ANK. S.43 & 4AbjSG51 \\
\hline 5 & KansasCollies & S.134 Ab70 & 5AbjSG51 \\
\hline 6 & BlueRibbon & S.154 Ab70 & 6AbjS3Ab70 \\
\hline 7 & SugarDrip & S.158 Ab70 & 7AbjS3Ab70 \\
\hline 8 & Hastings & SG.33 & 8AbjS3Ab70 \\
\hline 9 & N100 & SG.11 & 9AbjS3Ab70 \\
\hline 10 & N110 & SG.12-1 & 10AbjS3Ab70 \\
\hline 11 & N99 & SG.04 & 11AbjS3Ab70 \\
\hline 12 & Colman & SG.34 & 12AbjS3Ab70 \\
\hline 13 & Fremont & & 13AbjS3Ab70 \\
\hline 14 & & & 14AbjS3Ab70 \\
\hline 15 & & & 15AbjS3Ab70 \\
\cline { 1 - 3 } & & & \multicolumn{2}{|l}{}
\end{tabular}

Group 1= Sweet sorghum genotypes introduced from USA

Group 2= Selected from local populations Ankolib (ANK), Abu Sabin (Ab70) and Sudan grass (SG)

\section{Group 3= Selected from diversified local materials}

\section{The field experiment and collection of data}

The materials were sown on 19/2/2017 in Alwaha Project, Khartoum State $\left(15^{\circ} 21^{\prime} 05.0^{\prime \prime} \mathrm{N}\right.$, $\left.32^{\circ} 57^{\prime} 57.1^{\prime \prime E}\right)$. The materials were arranged in RCB design with 2 replicates. Seeds were sown on ridges by placing 3-4 seeds in holes spaced at $20 \mathrm{~cm}$. The plot composed of 2 ridges each $7 \mathrm{~m}$ long and $0.75 \mathrm{~m}$ apart. Irrigation water was applied at 7 to 10 day interval. Nitrogen fertilizer $(55 \mathrm{~kg} \mathrm{n} / \mathrm{ha})$ was applied at the second irrigation. Days to flower, stover yield, millable cane yield and brix (\%) were collected but will not be highlighted here. The plants in the whole plot were cut at physiological maturity of the grain, leaves and panicles were removed, the cane was washed and pressed using hand driven two-roller mill. The juice received was filtered using muslin cloth. Theoretical ethanol yield was worked out following Reddy et al., (2005) [3]. The actual ethanol yield was calculated by multiplying the percentage of ethanol from a fermented juice sample by the corresponding juice yield/ha.

\section{The Fermentation process}

The Baker's yeast (Saccharomyces cerevisiae) was revived at $32^{\circ} \mathrm{C}$ for 5 minutes using some of the sweet sorghum juice as growth medium. Fermentation of sweet sorghum juice was carried out in $200 \mathrm{ml}$ conical flasks. The $\mathrm{pH}$ was kept constant at 4.5 . The yeast (S. cerevisiae) was added ( $3 \mathrm{wt} \%)$ and the fermentation was carried out in an incubator at $30^{\circ} \mathrm{C}$ for 24 hours at a shaking speed of $120 \mathrm{rpm}$.

\section{Determination of ethanol}

The Ethanol determination was carried out in Alwatania Distillery Company - Khartoum North using Ebulliometer and a calculating device. $50 \mathrm{ml}$ were taken from the fermented sample and placed in the lower part of the Ebulliometer in which a thermometer was fixed. The fermented sample was boiled by a flame for $5-7 \mathrm{~m}$ until ethanol is fully evaporated. The boiling temperature is read with the 
corresponding size using the calculating device and the resulting value is equal to the percentage of ethanol size in the fermented sample.

\section{The statistical analysis}

The data were analyzed following the standard procedure of analyzing analysis of variance (ANOVA) for the RCB design [8]. Linear regression of the actual ethanol yield on theoretical yield was performed [9]. The statistical package of GenStat [10] was used to run the data analysis.

\section{Results}

Table 2 shows mean squares for ethanol and juice yields. Highly significant differences $(\mathrm{p} \leq$ 0.01) among genotypes were noticed for ethanol yields, whereas for juice yield differences were significant at $(\mathrm{p} \leq 0.05)$.

Ethanol yield: Table 3 shows the performance of genotypes in ethanol and juice yields. Percentage of ethanol from fermented samples ranged $4.75 \%-11.0 \%$ averaging $7.38 \%$. Most of the introduced materials yielded above average percentage, whereas the opposite is true for the local ones. Of the introduced materials, the best performing were Waconia-L (11\%), Red-x (9.85\%), N98 $(9.40 \%)$ and Brawley $(9.40 \%)$; the lowest performing were Colman $(6.75 \%)$ and N110 $(6.50 \%)$. The best performing among the local materials were 10AbjS3Ab70, 13AbjS3Ab70, 11AbjS3Ab70 and $15 \mathrm{AbjS} 3 \mathrm{Ab} 70$ with percent ethanol ranging $8.10 \%-8.80 \%$. Ankolib materials gave medium (7.31\%) to low (5.11\%) ethanol percentage obtained by ANK. S.18 and ANK. S.43, respectively. The lowest ethanol percentage were shown by SG.34 (4.80\%) and 7AbjS3Ab70 (4.75\%).

Actual ethanol yield averaged $572 \mathrm{~L} / \mathrm{ha}$ with a range of 124 to $1219 \mathrm{~L} /$ ha shown by SG34 and 5AbjSG51, respectively. Other top-ranking genotypes were S.154 Ab70 (1134 L/ha), Blueribbon $(1114 \mathrm{~L} / \mathrm{ha})$ and KensasCollies $(873 \mathrm{~L} / \mathrm{ha})$. It could be noticed that the three top-ranking genotypes in actual yield kept the same rank for juice yield, whereas, this may not necessarily be true for ethanol percentage. The genotype N98 which was the third-top in ethanol percentage was among the lowest ten in juice yield coupled with below average actual yield of $430 \mathrm{~L} / \mathrm{ha}$. In contrast, the genotype N110 which was among the lowest 10 in ethanol percentage was among the best 10 in actual yield and the best four in juice productivity. Juice yield ranged 2365- $15306 \mathrm{~L} / \mathrm{ha}$ with overall average of $7774 \mathrm{~L} / \mathrm{ha}$.

Theoretical ethanol yields were higher than actual ones ranging 192-1451 L/ha with overall average of $731 \mathrm{~L} / \mathrm{ha}$, yet, in most cases, the genotypes kept more or less close ranking in ethanol yield. The genotypes 5AbjSG51, S.154 Ab70, BlueRibbon and KensasCollies were also leading in theoretical yield with respective yields of 1220,1134, 1114 and $873 \mathrm{~L} / \mathrm{ha}$.

Table 4 shows correlation between ethanol and juice yields. Highly significant $(p=0.0001)$ strong positive correlation (0.919) was observed between actual ethanol yield and Juice yield. Highly significant positive correlation (0.614) was also observed between ethanol percentage and actual yield, however, correlation with juice yield (0.340) though positive, was not impressive.

Regression analysis: Tables 5 and 6 show ANOVA and estimates of parameters for regression of actual vs theoretical ethanol yield, respectively. Fig. 1 depicts fitted and observed relationship with $95 \%$ confidence limits for actual vs theoretical ethanol yield. The regression of actual on theoretical ethanol yield is highly significant with adjusted $\mathrm{R}^{2}$ amounting to 0.94 (i.e. $94 \%$ of the observations have been explained by the fitted model). Based on the parameter estimates (Table 6) the following equation was drawn for the fitted line in Fig. 1:

$$
\text { Actual ethanol yield }(\mathrm{L} / \mathrm{ha})=4.3+0.8007^{*} \chi
$$

where $\chi=$ theoretical ethanol yield. 


\section{Discussion}

Most of the variability observed among genotypes for ethanol yield could be attributed to genetic differences allowing identification of some promising materials for ethanol production. viz., BlueRibbon and KensasCollies from exotic materials; 5AbjSG51 and S.154 Ab70 from local materials. These varieties combined the best performance for ethanol percentage along with juice yield. The final ethanol yield/ha is the product of ethanol percentage and juice yield per ha. Having high ethanol percentage alone is not enough, it should be coupled with high juice yield. The low juice yield shown by this study $(2365-15306 \mathrm{~L} / \mathrm{ha})$ appeared to be a limiting factor for high ethanol productivity per hectare. For example, the genotype N98 which was among the best three in ethanol percentage, ranked quite low (28th) in actual ethanal yield owing to its low juice yield. This explains the relatively low ethanol yield shown by this study. The low juice yield may partially be attributed to the method used in juice extraction, namely: hand operated Two-Roller Mill. Using such types of mills results in less than $50 \%$ of juice being collected [11].

The results obtained for ethanol percentage from fermented juice are within the range or slightly higher than those reported in the literature. Maximum ethanol yield of $9 \%$ and $7.9 \%$ have been reported [12, 13]. Ethanol percentage ranges of 3.34\% - 9.53\% [14]; 8.3\% - 9.2\% [15] had been reported. Earlier studies reported ethanol yield percentages of 7.5\% [16] and 4.8\% [17]. All of the above workers studied ethanol yield in widely used commercial sweet sorghum varieties. In the Sudan, an average of $3.86 \%$ with a range of $2.13 \%-8.18 \%$ have been reported [18] for the varieties: Ankolib and Sugar Drip, respectively.

The regression analysis of actual vs theoretical yield revealed that the latter was little bit overestimated. The analysis was highly significant with sizable adjusted $\mathrm{R}^{2}$ value $(0.94 \%)$. Assuming linear relationship between the two yield parameters, actual yields could be estimated from theoretical ones by applying the formula suggested in equation (1). This will spare time, efforts and costs of laboratory and fermentation analysis.

Conclusion and recommendations: High potential exits for ethanol yield as percentage from fermented juice of some sweet sorghum varieties. However, juice yield is more crucial than ethanol concentration in maximizing ethanol yield of sweet sorghum. More efforts are needed to develop high juice-yielding genotypes. Juice maximization can also be achieved by using efficient milling devices and optimizing cultural practices

\section{Conflict of Interest}

The authors declare that there is no conflict of interest.

Table 2. Mean squares from analysis of variance (ANOVA) of ethanol and juice yields

\begin{tabular}{llllll}
\hline $\begin{array}{l}\text { Source of } \\
\text { variation }\end{array}$ & d.f. & Ethanol (\%) & $\begin{array}{l}\text { Ethanol actual } \\
\text { yield (L/ha) }\end{array}$ & $\begin{array}{l}\text { Ethanol theoretical } \\
\text { yield (L/ha) }\end{array}$ & $\begin{array}{l}\text { Juice yield } \\
\text { (L/ha) }\end{array}$ \\
\hline Rep & 1 & 12.393 & 319 & 22152 & 11890000 \\
Genotype & 37 & $3.887^{* *}$ & $154714^{* *}$ & $199028^{* *}$ & $17720000^{*}$ \\
Residual & 33 & 1.081 & 57341 & 77248 & 8748000 \\
C.V. $(\%)$ & & 14.1 & 41.9 & 38.0 & 38.0 \\
\hline
\end{tabular}

*,**: significant differences at $(0.05)$ and $(0.01)$ probability level, respectively. 
Table 3. Ethanol and juice yields (L/ha) of different sweet sorghum varieties

\begin{tabular}{|c|c|c|c|c|c|}
\hline S.No & Variety name & $\begin{array}{l}\text { Ethanol } \\
\text { yield }(\%)\end{array}$ & $\begin{array}{l}\text { Juice yield } \\
\text { (L/ha) }\end{array}$ & $\begin{array}{l}\text { Actual ethanol } \\
\text { yield (L/ha) }\end{array}$ & $\begin{array}{l}\text { Theoretical ethanol } \\
\text { yield (L/ha) }\end{array}$ \\
\hline 1 & Waconia-L & $11.00(1)^{*}$ & $7809(21)$ & $861 \quad(5)$ & $898(12)$ \\
\hline 2 & Red-x & $9.85 \quad(2)$ & $7109(25)$ & $692 \quad(13)$ & 741 (22) \\
\hline 3 & N98 & $9.40 \quad(3)$ & $4744(32)$ & $430 \quad(28)$ & $446(31)$ \\
\hline 4 & Brawley & $9.40 \quad(4)$ & $8484(18)$ & $794 \quad(7)$ & 935 (10) \\
\hline 5 & KensasCollies & $8.85 \quad(5)$ & $9859(6)$ & $873 \quad$ (4) & $1136(5)$ \\
\hline 6 & $10 \mathrm{AbjS} 3 \mathrm{Ab} 70$ & $8.80 \quad(6)$ & 8771 (16) & 781 & 899 (11) \\
\hline 7 & BlueRibbon & $8.65 \quad(7)$ & $12875(3)$ & $1114(3)$ & 1451 \\
\hline 8 & 13AbjS3Ab70 & $8.45 \quad(8)$ & 7403 (23) & $648 \quad(18)$ & $759(21)$ \\
\hline 9 & SugarDrip & $8.35 \quad(9)$ & $9828(7)$ & $827 \quad(6)$ & $1008(7)$ \\
\hline 10 & Hastings & $8.31 \quad(10)$ & $9040(15)$ & $659 \quad(16)$ & $946 \quad(9)$ \\
\hline 11 & N100 & $8.15 \quad(11)$ & $7788(22)$ & $635 \quad(19)$ & $838 \quad(17)$ \\
\hline 12 & 11AbjS3Ab70 & $8.10 \quad(12)$ & $8256(20)$ & $625 \quad(20)$ & $783 \quad(20)$ \\
\hline 13 & $15 \mathrm{AbjS} 3 \mathrm{Ab} 70$ & $8.10 \quad(13)$ & $9401(13)$ & 761 & 856 (14) \\
\hline 14 & N99 & $8.00 \quad(14)$ & 8309 (19) & $661 \quad(15)$ & 829 (18) \\
\hline 15 & 1AbjSG51 & $7.75 \quad(15)$ & 8656 (17) & $666 \quad(14)$ & $736(23)$ \\
\hline 16 & $8 \mathrm{AbjS} 3 \mathrm{Ab} 70$ & $7.65 \quad(16)$ & 9468 (12) & $719 \quad(11)$ & 809 (19) \\
\hline 17 & $9 \mathrm{AbjS} 3 \mathrm{Ab} 70$ & $7.55 \quad(17)$ & 9618 (11) & $718 \quad(12)$ & 854 (15) \\
\hline 18 & S. 134 Ab70 & $7.45 \quad(18)$ & $4482(35)$ & $335 \quad(30)$ & 354 (34) \\
\hline 19 & 5AbjSG51 & $7.41 \quad(19)$ & $15306(1)$ & 1219 & 1220 \\
\hline 20 & S.154 Ab70 & $7.40 \quad(20)$ & $14806(2)$ & 1134 (2) & 1322 (2) \\
\hline 21 & Fremont & $7.38 \quad(21)$ & $9677 \quad(8)$ & $572 \quad(22)$ & 875 (13) \\
\hline 22 & S.158 Ab70 & $7.38 \quad(22)$ & $10156(5)$ & $572 \quad(23)$ & $965(8)$ \\
\hline 23 & ANK. S.18 & $7.31 \quad(23)$ & 6627 (28) & $276 \quad(35)$ & $661(25)$ \\
\hline 24 & ANK.LzmNrs & $7.00 \quad(24)$ & 3765 & $280 \quad(34)$ & 295 \\
\hline 25 & ANK. S.36 & $6.85 \quad(25)$ & $3446 \quad(38)$ & $240 \quad(37)$ & 295 (38) \\
\hline 26 & $14 \mathrm{AbjS} 3 \mathrm{Ab} 70$ & $6.75 \quad(26)$ & $9628 \quad(10)$ & $659 \quad(17)$ & $1014(6)$ \\
\hline 27 & 4AbjSG51 & $6.75 \quad(27)$ & $4597 \quad(33)$ & $308 \quad(33)$ & 355 \\
\hline 28 & Colman & $6.75 \quad(28)$ & $6468(29)$ & $437 \quad(26)$ & 647 (26) \\
\hline 29 & 12AbjS3Ab70 & $6.55 \quad(29)$ & 9068 (14) & $591 \quad(21)$ & $699(24)$ \\
\hline 30 & N110 & $6.50 \quad(30)$ & $10800(4)$ & $724 \quad(10)$ & $1217(4)$ \\
\hline 31 & 3AbjSG51 & $6.50 \quad(31)$ & $4986 \quad(31)$ & $314 \quad(32)$ & $404(32)$ \\
\hline 32 & SG.33 & $6.35 \quad(32)$ & $5689 \quad(30)$ & $361 \quad$ (29) & $511(30)$ \\
\hline 33 & SG.11 & $6.30 \quad(33)$ & $4576 \quad(34)$ & $254 \quad(36)$ & 353 \\
\hline 34 & 2AbjSG51 & $6.15 \quad(34)$ & $6907 \quad(26)$ & $446 \quad(25)$ & $533(27)$ \\
\hline 35 & SG.12-1 & $5.95 \quad(35)$ & 9639 (9) & $560 \quad(24)$ & 841 (16) \\
\hline 36 & $6 \mathrm{AbjS} 3 \mathrm{Ab} 70$ & $5.85 \quad(36)$ & $7358 \quad(24)$ & $431 \quad(27)$ & 513 (29) \\
\hline 37 & SG.04 & $5.70 \quad(37)$ & $2365 \quad(40)$ & $135 \quad(38)$ & 195 (39) \\
\hline 38 & ANK. S.43 & $5.11 \quad(38)$ & 4031 & 134 (39) & $334(36)$ \\
\hline 39 & SG.34 & $4.80 \quad(39)$ & 2474 (39) & 124 (40) & $192(40)$ \\
\hline 40 & 7AbjS3Ab70 & $4.75 \quad(40)$ & $6689 \quad(27)$ & $323 \quad(31)$ & $516(28)$ \\
\hline Mean & & 7.38 & 7774 & 572 & 731 \\
\hline $\mathrm{SE} \pm$ & & 0.735 & 2091.4 & 169.3 & 196.5 \\
\hline
\end{tabular}

*: Figure between brackets denotes rank

Table 4. Correlation between ethanol and juice yields

\begin{tabular}{llllc}
\hline Parameters & \multicolumn{1}{c}{$\begin{array}{c}\text { Cor. } \\
\text { Coefficient }\end{array}$} & P-Value & $\begin{array}{c}95 \% \\
\text { Lower }\end{array}$ & $\begin{array}{c}\text { 95\% } \\
\text { Upper }\end{array}$ \\
\hline Juice yield with Actual ethanol yield & 0.919 & $<0.0001$ & 0.851 & 0.957 \\
Ethanol yield (\%) with Actual ethanol yield & 0.614 & $<0.0001$ & 0.373 & 0.777 \\
Ethanol yield (\%) with Juice yield & 0.340 & 0.0310 & 0.032 & 0.589 \\
\hline
\end{tabular}


Table 5. Regression ANOVA of actual vs theoretical ethanol yield

\begin{tabular}{llllll}
\hline Source & d.f. & s.s. & m.s. & v.r. & F pr. \\
\hline Regression & 1 & 6260433 & 6260433 & 673.12 & $<.001$ \\
Residual & 70 & 651040 & 9301 & & \\
Total & 71 & 6911473 & 97345 & & \\
\hline
\end{tabular}

Percentage variance accounted for $=90.4$

Standard error of observations is estimated to be 96.4.

Table 6. Estimates of parameters of actual vs theoretical ethanol yield

\begin{tabular}{lllll}
\hline Parameter & estimate & s.e. & $\mathrm{t}(70)$ & $\mathrm{t}$ pr. \\
\hline Constant & 4.3 & 24.7 & 0.18 & 0.861 \\
Theoretical ethanol yield $(\mathrm{L} / \mathrm{ha})$ & 0.8007 & 0.0309 & 25.94 & $<.001$ \\
\hline
\end{tabular}

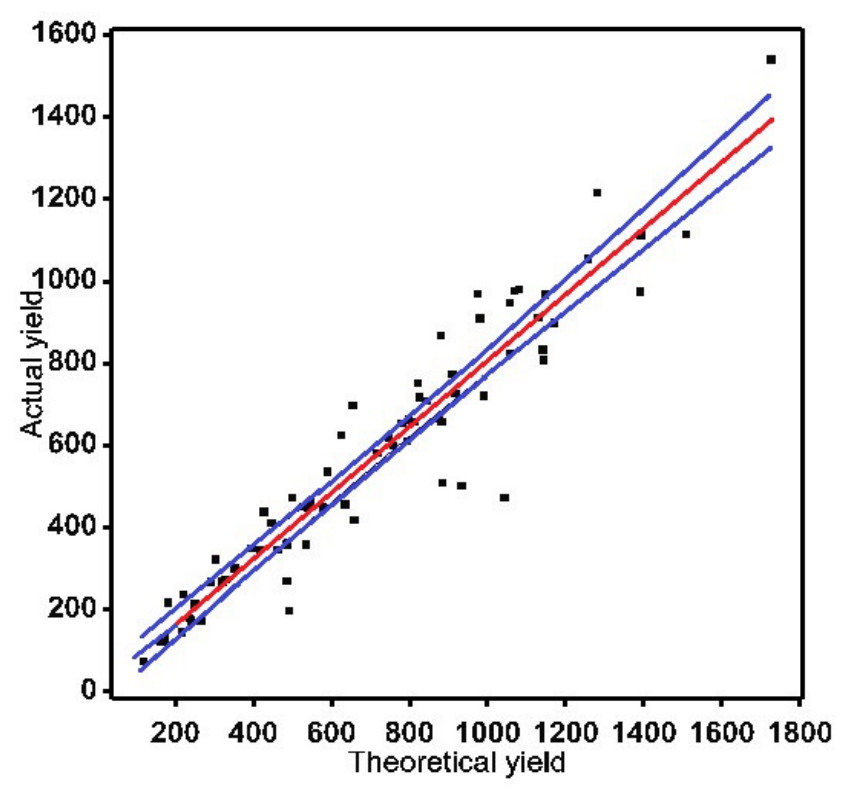

Fig. 1. Fitted and observed relationship with $95 \%$ confidence limits for actual vs theoretical ethanol yield

\section{References}

[1] A. Beldados, L. Constantini, Sorghum exploitation at Kassala and its environs, north eastern Sudan in the second and first millennia BC, Nyame Akuma. 75 (2011) 33-39.

[2] D.Q. Fulle, Early Kushite agriculture: Archaeobotanical evidence from Kawa, Sudan and Nubia. 8 (2004) 70-74.

[3] B.VS. Reddy, S. Ramesh, P.S. Reddy, B. Ramaiah, P.M. Salimath, R. Kachapur, Sweet sorghum - A potential alternate raw material for bio-ethanol and bioenergy, ISMN. 46 (2005) 79-83.

[4] Maarouf I. Mohammed, Annual scientific report, Shambat Research Station, Agricultural Research Corporation, Wad Medani, Sudan. (2012) Available at: https://www.researchgate.net/ profile/Maarouf_Mohammed2

[5] S. I. Abdalbagi, M. I. Mohammed, Concurrent improvement of stem sugar, stover and grain yield in Sudanese and exotic sorghums, I: Identification of materials, Journal of Advances in Biology \& Biotechnology. 17(2018)1-8.

[6] K.M. Dombek, L.O. Ingram, Nutrient limitation as a basis for the apparent toxicity of low levels of the ethanol during fermentation, J. Ind. Microbiol. 1 (1986) 219-225. 
[7] W.K. Bronn, Screening of yeasts associated with food from the Sudan and their possible application for single cell protein and ethanol production, Ph.D. Thesis, Technologie derhefe fabrikation, script., T.U. Berlin. (1982) P. 26.

[8] W.G. Cochran, G. M. Cox, Experimental designs, 2nd ed. (1957) Wiley, New York.

[9] R.W. Payne, S.A. Harding, D.A. Murray, D.M. Soutar, D.B. Baird, S.J. Welham, A.F. Kane, A.R. Gilmour, R., Thompson Webster, R. G. Tunnicliffe Wilson, Linear regression, IN: GenStat for Windows, VSN International. 10 (2007) 157-166.

[10] Genstat, Ninth edition, Version - 9.1.0.174, Lawes Agricultural Trust (Rothamsted Experimental Station), VSN International, (2009) Hertfordshire, UK.

[11] M.W. Veal, M.S. Chinn, L.F. Stikeleather, M.B. Whitfield, Sweet sorghum ethanol production, North Carolina Cooperative Extension, 14-CALS-4052. (2014) AG-786.—BS/BS.

[12] C.V. Ratnavathi, K. Suresh, B.S. Vijay Kumar, M. Pallavi, V.V. Komala, N. Seetharama, Study on genotypic variation, Sugar Tech. 13 (2010) 399-407.

[13] D.K. Kundiyana, D. D. Bellmer, R.L. Huhnke, M.R. Wilkins, P.L. Claypool, Influence of temperature, $\mathrm{pH}$ and yeast on in-field production of ethanol from unsterilized sweet sorghum juice, Biomass and Bioenergy. 3 (2010) 1481-1486.

[14] D.S. Horton, Evaluation of sweet sorghum cultivars as a potential ethanol crop in Mississippi, A thesis submitted to the faculty of Mississippi State University. (2011).

[15] T. Imam, S. Capareda, Fermentation kinetics and ethanol production from sweet sorghum, Int J Agric \& Biol Eng. 4 (2011) 33-40.

[16] V. Lezinou, P. Christakopoulo, L.W. Li, D. Kekos, B.J. Macris, Study of a single and mixed culture for the direct bioconversion of sorghum carbohydrate to ethanol, Applied Microbiology and Biotechnology. 43 (1995) 412-415.

[17] D. Mamma, P. Christakopoulos, D. Koullas, D. Kekos, B.J. Macris, E. Koukios, Alternative approach to the bioconversion of sweet sorghum carbohydrates to ethanol, Biomass and Bioenergy. 8 (1995) 99-103.

[18] Y. H. Batoul, Evaluation of some sweet sorghum genotypes for ethanol production. M.Sc. theses, Faculty of Agriculture, University of Khartoum. (2006). 